\title{
GAS PROPORTIONAL VERSUS LIQUID SCINTILLATION COUNTING, RADIOMETRIC VERSUS AMS DATING
}

\author{
PÁLL THEODÓRSSON
}

Science Institute, University of Iceland, Dunhaga 3, 107 Reykjavík, Iceland

\begin{abstract}
I discuss here the basis of a comparison of methods for radiocarbon dating and introduce a new index for the relative merit of a system, factor of counting capacity, that is generally more appropriate than the commonly used factor of merit. The merit of a dating system cannot be based on a single figure but other factors must also be considered. A comparison of the gas proportional, liquid scintillation and accelerator mass spectrometry technique is presented that for gas proportional counters is based on a multi-detector system rather than a single detector.
\end{abstract}

\section{INTRODUCTION}

Williard $\mathrm{F}$ Libby developed radiocarbon dating some 40 years ago. The gas proportional counting (GPC) technique, pioneered by Hessel de Vries, soon replaced Libby's solid carbon method. A decade later, liquid scintillation counting (LSC) was introduced to the field and some ten years ago, the powerful accelerator mass spectrometry (AMS) technique was established.

LSC systems were soon developed to a high technical standard by a number of firms and sold at a moderate price. These commercial systems have been used for dating with little or no modifications. Until some five years ago, GPC systems generally performed better because of lower background and greater stability. This difference has vanished in recent years with the introduction of LSC systems designed specifically for low-level work.

At present, GPC systems are not made commercially, and their development has been slow during the past decade. Presumably scientists have been waiting to see what the development of the AMS technique would bring.

We now have three competing, partly complementary, methods for ${ }^{14} \mathrm{C}$ dating. A good comparison of their relative merits is needed. The present paper is a contribution to the discussion of the comparison; it re-evaluates the merit of the GPC method, which, in recent years, has been underestimated because single detector systems, rather than multidetector systems, have been considered in comparisons.

First, the basis of the comparison is discussed, then, data on some high-performance GPC and LSC systems follows, and finally, the three methods are compared.

\section{COMPARISON OF LSC AND GPC SYSTEMS}

The performance of ${ }^{14} \mathrm{C}$ dating systems is usually measured by their factor of merit (FOM), given by $S_{o} / \sqrt{ } B$ where $S_{o}$ is the net count rate of a recent standard ( 0.95 oxalic acid standard) and $\mathrm{B}$ the background. This is, however, a serious simplification, as will be discussed below. Let us look at the full expression, from which the FOM is derived. The relative standard deviation $\varepsilon$ of the net sample count rate S is given by (Watt \& Ramsden 1964; Oeschger \& Wahlen 1975):

$$
\varepsilon^{2}=\left((\mathrm{S}+\mathrm{B}) / \mathrm{T}_{\mathrm{S}+\mathrm{B}}+\mathrm{B} / \mathrm{T}_{\mathrm{B}}\right) / \mathrm{S}^{2}
$$

where $T_{S+B}$ and $T_{B}$ are the counting times of the sample and background. In radiocarbon dating, the background is only measured periodically and a corrected mean value over a long time is used. Thus, the background will generally be known with better accuracy than the sample count rate $S$, (Mook \& Streurman 1983). Thus, the term, $\mathrm{B} / \mathrm{T}_{\mathrm{B}}$, in equation (1) can be omitted. In this case, 
the sample counting time will be given by:

$$
\mathrm{T}_{\mathrm{S}+\mathrm{B}}=(1+\mathrm{B} / \mathrm{S}) /\left(\varepsilon^{2} \cdot \mathrm{S}\right)
$$

The number of samples that can be measured per unit time to a given accuracy, the systems counting capacity, is a natural measure for the merit of a system. This is inversely proportional to the counting time, so I define the factor of counting capacity, FCC, by:

$$
\mathrm{FCC}=\mathrm{S} /(1+\mathrm{B} / \mathrm{S})
$$

For young samples where $S>B$, the $F C C$ is close to $S$. For the oldest samples where $S<B$, the factor of counting capacity approaches $\mathrm{S}^{2} / \mathrm{B}$, and this will be a measure of the maximum age that can be determined with the system in a given counting period. The factor of merit, FOM, which is actually a measure of the counting capacity of the oldest measurable samples where $S<B$, is based on $1 / \sqrt{ } \mathrm{T}$ rather than $1 / \mathrm{T}$, and therefore:

$$
\mathrm{FOM}=\mathrm{S} / \sqrt{\mathrm{B}}
$$

where again the counting rate of recent standard is again used for the sample count rate.

If the majority of samples to be measured are very old $(\mathrm{S}<\mathrm{B})$, the FOM is an appropriate measure of the merit of the counting system. However, in dating it is more common that the majority of samples have an age under 10,000 years where the net sample count rate is larger than the background. The factor of counting capacity is then a more appropriate basis for the comparison of systems, and $\mathrm{S}$ or $\mathrm{S}_{\mathrm{o}}$ is then usually a good measure for the FCC.

If the system has $\mathrm{N}$ identical sample counters with the same $\mathrm{S} / \mathrm{B}$ ratio, it is evident that the counting capacity of the system will be $\mathrm{N}$ times larger than for individual counters:

$$
\mathrm{FCC}_{\mathrm{N}}=\mathrm{N} \cdot \mathrm{S} /(1+\mathrm{B} / \mathrm{S})
$$

Similarly, the FOM for this system will be given by:

$$
\mathrm{FOM}_{\mathrm{N}}=\sqrt{\mathrm{N}} \cdot \mathrm{S} / \sqrt{ } \mathrm{B} \text {. }
$$

When dating systems are compared, $\mathrm{S}_{0}$, the $95 \%$ count rate of oxalic acid, is used instead of the unspecified count rate, $\mathrm{S}$, in the formulae above.

Although a multicounter system with 7-10 sample detectors is technically somewhat more complex than a modern low-level LSC system, it is more appropriate to base a comparison of LSC systems with a multidetector GPC system rather than a single detector. It takes somewhat less time to prepare $1.0 \mathrm{~g}$ carbon in the form of $\mathrm{CO}_{2}$ for the gas proportional system than a standard 3 or $5 \mathrm{ml}$ benzene sample.

The size of available sample is quite often limited. Although LSC can measure $20 \mathrm{ml}$ of benzene, the standard sample size is usually $3-5 \mathrm{ml}(2.4-4.0 \mathrm{~g}$ carbon). If the sample size falls below the standard size, the net count rate will fall proportionally as will the FOM and FCC. A modern multidetector GPC system might have eight sample detectors taking about $1.0 \mathrm{~g}$ carbon each. Thus, undersized samples will be considerably less frequent with a GPC than an LSC.

The multicounter system will offer a further advantage of parallel counting. One of the samples would always be a background sample. This will give continuous monitoring of the background. Further, the coincidence count rate will be the same in all elements and this allows for checking the proper functioning of the system. 


\section{GAS PROPORTIONAL COUNTING SYSTEMS}

Conventional GPC systems consist of a sample detector surrounded by an active shield (guard counter system), either an annular gas proportional counter or an array of long cylindrical proportional or Geiger detectors. A layer of mercury or old lead ( $\mathrm{Pb}-210$ free), $2-5 \mathrm{~cm}$ thick, is inserted between the sample detector and guard counter system. A layer of boronated paraffin, $5-10 \mathrm{~cm}$ thick, usually surrounds the guard counter system to absorb neutrons formed by cosmic rays in the enclosing passive shield, which consists of a layer of lead, $10-15 \mathrm{~cm}$ thick, or $20-30 \mathrm{~cm}$ iron.

The background pulses originate from direct ionization in the gas and from electrons released from a thin layer of the inner surface of the counter wall after primary ionization in the wall. Based on extensive experience, Robinson (1976) offered the following empirical equation for the target background, $\mathrm{B}(\mathrm{t})$, of a good proportional counter:

$$
\mathrm{B}(\mathrm{t})=0.0081 \cdot \mathrm{M}+5 \cdot 10^{-4} \cdot \mathrm{A} \mathrm{cpm}
$$

where $\mathrm{M}$ is the mass $(\mathrm{g})$ of the gas and $\mathrm{A}$ is the inner surface area $\left(\mathrm{cm}^{2}\right)$ of the sample counter. It should be noted that only the best gas counters reach this target. Frequently, the background is 2-3 times higher.

Equation (7) is convenient when comparing the background of counters with different volumes and working pressure. Table 1 presents characteristic parameters of four high-performance GPC systems. The volume is determined from the active length of the anode wire.

TABLE 1

Comparison of some GPC systems

\begin{tabular}{lcccccccc}
\hline $\begin{array}{l}\text { System } \\
\text { no. }\end{array}$ & $\begin{array}{c}\text { Volume } \\
\text { (liter) }\end{array}$ & $\begin{array}{c}\text { Pressure } \\
(\mathrm{atm})\end{array}$ & $\begin{array}{c}\mathrm{S}_{\mathrm{o}} \\
(\mathrm{cpm})\end{array}$ & $\begin{array}{l}\mathrm{B}, \mathrm{cpm} \\
(\mathrm{meas})\end{array}$ & $\begin{array}{c}\mathrm{B}(\mathrm{t}), \mathrm{cpm} \\
(\mathrm{calc})\end{array}$ & $\mathrm{B} / \mathrm{B}(\mathrm{t})$ & $\begin{array}{c}\mathrm{S}_{\mathrm{o}} / \sqrt{\mathrm{B}} \\
(\mathrm{FOM})\end{array}$ & Laboratory \\
\hline 1 & 1.04 & 2.5 & 16.6 & 0.50 & 0.43 & 1.17 & 23.4 & Menlo Park \\
2 & 1.5 & 2.0 & 19.4 & 0.69 & 0.69 & 1.0 & 23.4 & Trondheim \\
3 & 0.98 & 5.66 & 34.0 & 1.34 & 0.57 & 2.4 & 29.4 & Groningen \\
4a & 1.04 & 3.40 & 24.1 & 0.69 & 0.54 & 1.28 & 29.0 & Helsinki \\
4b & With PRA* $^{*}$ & 3.40 & 19.7 & 0.21 & 0.54 & 0.39 & 43.0 & - \\
\hline
\end{tabular}

*PRA, pulse rise analysis, see below.

It is worth noting that neither System 2 (Nydal, Gulliksen \& Lövseth 1975) nor 4 (Mäntynen et al 1987) have a neutron absorbing layer. System 1 is in a laboratory shielded by ca $8 \mathrm{~m}$ of soil layer (Robinson 1981).

The introduction a decade ago of multicounter systems to radiocarbon dating marked an important improvement (Schoch et al 1980; Tans et al 1982). These systems have 7-10 identical sample detectors operating at the same pressure and sharing a single high-voltage power supply. A minicomputer replaces ca $80 \%$ of the conventional electronic equipment previously required for such a system. System 3 (Table 1) represents one of these (Tans et al 1982), located in Groningen, The Netherlands, with seven sample detectors.

Important improvements were recently introduced in the GPC technique at the University of Helsinki (System 4 (Table 1); Mäntynen et al 1987). An annular LSC is used as a guard counter for three sample detectors, which are neither shielded with boronated paraffin nor an inner shield. Pulse rise analysis (PRA) is used to reject the slower rising background pulses. This reduces the counting efficiency by $18 \%$, but at the same time, the background is reduced by a factor of 3.3 ! 
The figures given in Table 1 are more recent values (T Kankainen, pers commun 1989). The low background count rate of this system without PRA demonstrates the high efficiency of the liquid scintillation guard.

It is easy to adapt the multidetector GPC technique to small samples (Hut, Kayser \& Wijma 1983; Otlet, Huxtable \& Sanderson 1986; Jelen \& Geyh 1986).

Considering the various improvements that have been made in GPC systems in past years, it seems probable that the technique could be improved considerably if these were incorporated systematically into a single new system.

\section{LIQUID SCINTILLATION COUNTING SYSTEMS}

Practically all earlier LSC systems used for ${ }^{14} \mathrm{C}$ dating were standard commercial equipment produced for general tracer work. Five years ago, a new LSC system, Quantulus from Wallac, was designed for low-level work. It has an annular liquid scintillation guard counter and a thicker lead shield than other commercial systems. More recently, Packard introduced a simpler LSC system (2260XL) for low-level work.

Polach et al (1988) recently published a comparison of some LSC systems. Table 2 is based on Polach's data with the addition of Packard's 2260XL system (GT Cook, pers commun 1990). The superiority of the technical specifications of the Quantulus system is evident, but it is more expensive.

TABLE 2

Comparison of LSC systems; sample $=3 \mathrm{ml}$ benzene

\begin{tabular}{lllllc}
\hline \multicolumn{1}{c}{ System } & Vial & $\begin{array}{c}\mathrm{B} \\
(\mathrm{cpm})\end{array}$ & $\begin{array}{l}\mathrm{S}_{\mathrm{o}} \\
(\mathrm{cpm})\end{array}$ & $\begin{array}{l}\text { Counting } \\
\text { efficiency }\end{array}$ & $\mathrm{S}_{\mathrm{o}} / \sqrt{ } \mathrm{B}$ \\
\hline 1. Packard 2000CA/LL & Glass & 1.01 & 17.9 & $54.2 \%$ & 18 \\
2. Packard 2060XL & Teflon & 0.69 & 23.6 & $71.4 \%$ & 24 \\
3. Quantulus & Teflon & 0.21 & 25.2 & $76.4 \%$ & 55 \\
4. Quantulus, low-level lab & Teflon & 0.14 & 23.1 & $70.0 \%$ & 62 \\
\hline
\end{tabular}

TABLE 3

A comparison of the AMS, LSC and GPC methods

\begin{tabular}{lllll}
\hline Parameters & AMS & Quantulus & GPC & Multi-GPC \\
\hline Sample weight & $1 \mathrm{mg}$ & $2.6 \mathrm{~g}$ & $2.6 \mathrm{~g}$ & $2.73 \mathrm{~g}$ \\
Modern count rate, $\left(\mathrm{S}_{\mathrm{o}}\right), \mathrm{cpm}$ & 900 & 26.5 & 30 & $34\left(238^{*}\right)$ \\
Background $(\mathrm{B}), \mathrm{cpm}$ & 3.78 & 0.18 & 0.75 & 1.3 \\
Background, \% modern & 0.42 & 0.66 & 2.4 & 3.9 \\
Factor of merit $\left(\mathrm{S}_{\mathrm{o}} / \sqrt{ } \mathrm{B}\right)$ & 462 & 63 & 35 & $29.8\left(78^{*}\right)$ \\
Precision, modern sample & $52 \mathrm{yr}$ & $35 \mathrm{yr}$ & $35 \mathrm{yr}$ & $35 \mathrm{yr}$ \\
Samples per day (no breakdown) & 7 & 0.7 & 0.7 & 6.6 \\
Cost per analysis** & $\$ 500$ & $\$ 250$ & $\$ 250$ & $\$ 250$ \\
\hline
\end{tabular}

*Taking 7 elements into account

${ }^{* *}$ Cost includes measurement of ${ }^{13} \mathrm{C}$ fractionation 


\section{RADIOMETRIC VS AMS DATING}

A powerful new technique for measuring the ${ }^{14} \mathrm{C} /{ }^{12} \mathrm{C}$ ratio was introduced some 10 years ago when mass spectrometry was applied to the ionic beam from a Tandem Van de Graaf accelerator. In this technique, the number of ${ }^{14} \mathrm{C}$ atoms are counted after a careful mass as well as atomic number separation. How do the modern radiometric systems compare to this new technique?

Damon (1989) has compared the AMS dating technique with the Quantulus and a single gas proportional counter. Table 3 shows Damon's comparison as well as Groningen's multidetector system. The comparison shows that the multidetector system is highly competitive.

The AMS technique has a clear superiority over the radiometric methods for dating samples of submilligram size. However, the equipment needed is expensive and bulky.

\section{CONCLUSION}

For comparison, the FCC is usually the best indicator of the merit of a system, but when the bulk of samples is old, FOM should be used. Further, the frequency of undersized samples should be considered. The choice of a system will depend on commercial availability, the facilities the scientist has for setting up a GPC system, and his/her personal experience. Finally, the price of the counting equipment should be considered.

Considering the comparison in Table 3, available sample size distribution, expense of experimental facilities and the total price of dating, it seems likely that both radiometric and AMS techniques will be used side by side for many years to come, complementing each other very well. For a sample size down to ca $0.1 \mathrm{~g}$ carbon that can still be dated to $1 \%$ in a week, the gas proportional multidetector system looks very attractive.

In view of the potentialities of the AMS technique, many researchers seem to have hesitated to develop further the GPC technique. In view of the comparison in Table 3, further development of gas proportional systems is to be encouraged as long as major improvements are not made in the AMS technique.

\section{REFERENCES}

Damon, P (ms) 1989 Radiocarbon dating techniques: TAMS versus Quantulus. In preparation.

Hut, G, Kayser, J and Wijma, S 1983 A multiple proportional ${ }^{14} \mathrm{C}$ counter system for milligram-sized samples. In Stuiver, $\mathrm{M}$ and Kra, RS, eds, Internatl ${ }^{14} \mathrm{C}$ conf, 11th, Proc. Radiocarbon 25(2): 547-552.

Jelen, $\mathrm{K}$ and Geyh, MA $1986 \mathrm{~A}$ low-cost miniature counter system for radiocarbon dating. In Stuiver, M and Kra, RS, eds, Internatl ${ }^{14} \mathrm{C}$ conf, 12th, Proc. Radiocarbon 28(2A): 578-585.

Mäntynen, P, Äikää, O, Kankainen, T and Kaihola, L 1987 Application of pulse-shape discrimination to improve the precision of the carbon-14 gas-proportional-counting method. Appl Radiat Isot 38(10): 869-873.

Mook, WG and Streurman, HJ 1983 Physical and chemical aspects of radiocarbon dating. PACT 8: 31-56.

Nydal, R, Gulliksen, S and Lövseth, K 1975 Proportional counters and shielding for low level gas counting. In Povinec, P, ed, Internatl conference on Low-radioactivity: measurements and applications. High Tatras, Proc: 77-84.

Oeschger, H and Wahlen, M 1975 Low level counting technique. Ann Rev Nuclear Sci: 423-463.

Otlet, RL, Huxtable, G and Sanderson, DCW 1986 The development of practical systems for ${ }^{14} \mathrm{C}$ measurement of small samples using miniature counters. In Stuiver, $\mathrm{M}$ and $\mathrm{Kra}$, RS, eds, Internatl ${ }^{14} \mathrm{C}$ conf, 12th, Proc. Radiocarbon $28(2 \mathrm{~A})$ : 603-614.

Polach, H, Calf, G, Harkness, D, Hogg, A, Kaihola, L and Robertson, S 1988 Performance of new technology liquid scintillation counters for ${ }^{14} \mathrm{C}$ dating. Nuclear Geophysics 2.

Robinson, SW 1976 Radiocarbon dating at the US Geological Survey, Menlo Park, California. In Berger, R and Suess, HE, eds, Radiocarbon dating. Internatl ${ }^{14} \mathrm{C}$ conf, 9th, Proc. Berkeley, Univ California Press: 268-273.

Robinson, SW and Trimble, DA 1981 US Geological Survey, Menlo Park, California, radiocarbon measurements II. Radiocarbon 23(2): 305-321.

Schoch, H, Bruns, M, Münnich, KO and Münnich, M 1980 A multi-counter system for high precision carbon-14 measurements. In Stuiver, $M$ and Kra, RS, eds, Internatl ${ }^{14} \mathrm{C}$ conf, 10th, Proc. Radiocarbon 22(2): 442-447.

Tans, PP, de Jong, AFM, Mook, WG and Hut, G 1982 High accuracy carbon-14 counting and the application to the radiocarbon calibration curve. In Povinec, P, ed, Conference on low-level counting, 2nd, Proc. Bratislava: 155-169.

Watt, DE and Ramsden, D 1964 High sensitivity counting technique. London, Pergamon Press: 2. 